\title{
El paisaje en el texto. El paisaje del texto. Elementos petrarquistas en la poesía de Ramón López Velarde
}

\author{
Luca SALVI \\ Università di Bologna \\ Luca.salvi3@unibo.it
}

Sentio inexpletum quoddam in praecordiis meis semper

FRANCESCO PETRARCA

\begin{abstract}
RESUMEN
Una atenta lectura del Canzoniere de Petrarca revela el texto como el lugar donde el yo se construye y estructura, siguiendo el movimiento oscilatorio propio del sentimiento eróticoamoroso. A partir de esta perspectiva, el artículo se propone reconocer, en las referencias al paisaje en la poesía de Ramón López Velarde, características y funciones análogas a las que el mismo elemento tiene en la obra de Petrarca. El peculiar modo de empleo del paisaje aclara una lógica que condiciona de manera más amplia el entero tejido textual, proporcionando las herramientas adecuadas para volver a evaluar las modalidades de supervivencia, en la poesía moderna y contemporánea, de la lección petrarquesca original.
\end{abstract}

Palabras clave: López Velarde, petrarquismo, erotismo, paisaje, ambientación

\begin{abstract}
A perusal of the Petrarch's Canzoniere reveals the text as the place where the self builds and structures itself, following the typical oscillation of eroticism and love. From this interpretation, the paper aims to identify, in Ramón López Velarde's poetic use of settings, similarities of traits and functions with the same element in the Petrarchan poetry. The peculiar way settings are used allows to focus a logic that deeply permeates the whole text, providing suitable instruments to revalue the way the original Petrarchan lesson survives in modern and contemporary poetry.
\end{abstract}

Keywords: López Velarde, petrarchism, eroticism, landscape, setting

Sumario: 1. Introducción 2. Erotismo y palabra poética 3. Construcción del paisaje 4. Conclusiones 


\section{Introducción}

Adentrarse en la tan compleja e incierta galaxia del petrarquismo contemporáneo significa, en primera instancia, renunciar a esquemas de lectura que, nacidos en particular como herramientas interpretativas para el estudio de la lírica europea de los siglos XVI y XVII, resultarían, si fueran aplicadas a experiencias poéticas modernas y contemporáneas, anacronismos sin sentido, de escasa utilidad para un enfoque crítico de la materia. Por esto, se hace indispensable el establecimiento de una nueva red de coordenadas que permitan individualizar, en casos específicos, concretas reelaboraciones de un discurso poético arquetípico, como es el caso del modelo petrarquesco: dejar entonces de lado constantes estilísticas y temáticas manieristas que sellaron el petrarquismo histórico europeo para internarse en la búsqueda de invariantes textuales que demuestren la presencia de analogías, en la modernidad poética, con el discurso petrarquesco.

Con este objetivo se analizará la poesía del mexicano Ramón López Velarde, dado que ésta constituye una experiencia fundamental y fundacional de la poesía hispanoamericana del siglo XX. Además, la lírica velardeana proporciona interesantes elementos útiles para elaborar modelos críticos nuevos, aptos para investigar el fenómeno del petrarquismo incluso en experiencias poéticas que parecen distanciarse, diatópica y diacrónicamente. En este sentido se propondrá una interpretación de los elementos ambientales y paisajísticos velardeanos que permitan establecer interesantes paralelos con la lección petrarquesca.

\section{Erotismo y palabra poética}

Para empezar, es necesario fijar algunas coordenadas que resultarán útiles a la hora de analizar los textos, ayudando a colocar la poesía de Ramón López Velarde en el marco de una tradición lírica inaugurada por Francesco Petrarca y su Canzoniere. En primera instancia, es evidente que ambos autores, López Velarde y Petrarca, comparten una idea de poesía como escritura erótico-amorosa. Como sostiene Octavio Paz en relación con la poesía velardeana, aunque la afirmación resulte reductiva, "el amor es su tema"1. Sin embargo, importa destacar cómo el sentimiento de amor es exclusivamente un medio - diríamos un pretexto - del cual nuestros autores se sirven para realizar un discurso cuyo centro y referente único es el mismo yo que lo pronuncia. En el caso de López Velarde, esta peculiar función de la lírica amorosa aparece satisfactoriamente explicada por el mismo poeta en la breve prosa "La Soez", incluida en El Minutero. Aludiendo a su constante referencia a lo femenino a lo largo de toda su poesía, el escritor afirma: "[...] nada puedo entender ni sentir sino a través de la mujer [...]. De aquí que a las mismas cuestiones abstractas me llegué con temperamento erótico"2. De modo que los

${ }^{1}$ O. Paz (1969), p. 91.

${ }^{2}$ R. López Velarde (1998), p. 320. 
poemas de amor no son, en el poeta mexicano, sino "auscultaciones de un espíritu inquieto que se toma el pulso, confesiones de un solitario, monólogos en los que el alma y el cuerpo se desdoblan y se interrogan mutuamente" ${ }^{3}$.

En la opinión de uno de los más autorizados críticos de la obra velardeana, Allen Whitmarsh Phillips, el lenguaje es, para el poeta mexicano, "el único modo factible para la objetivación de sus auténticas preocupaciones espirituales" ${ }^{4}$, de tal modo que el amor, en su declinación literaria y dada la ecuación por la cual expresión lingüística y espíritu se corresponden recíprocamente, se vuelve el telón de fondo sobre el cual proyectar las contradictorias imágenes de su propio ser; el amor es la transfiguración verbal de un conflicto. Conflicto cuyas raíces es necesario encontrar en el deseo mismo de ser, existir como entidad homogénea y no fragmentada, a pesar de las contradicciones que afligen al sujeto en el presente. El concepto lacaniano de manque bien explica este estado del sujeto:

Le désir est un rapport d'être à manque. Ce manque est manque d'être [...]. Ce n'est pas manque de ceci ou de cela, mais manque d'être par quoi l'être existe. [...] L'être vient à exister en fonction même de ce manque. [...] Dans ce manque d'être, [le sujet] s'aperçoit que l'être lui manque, et que l'être est là, dans toutes les choses qui ne savent pas être 5 .

Su condición es la de la alternancia ética: en él conviven pulsiones opuestas que le impiden reconocerse unívocamente. Esto lleva a la constatación de una falta de ser como falta de una identidad precisa. Alternantes dudas que generan, en la poesía velardeana, constantes "afirmaciones de dualidad" del sujeto 7 . De aquí el deseo de volver a un estado de plenitud del ser que en su trasposición simbólica al discurso amoroso sería entonces la unión de los amantes ${ }^{8}$. El erotismo, en su naturaleza de movimiento de síntesis entre un yo y un otro hacia un nosotros de equilibrio, es capaz de representar, por lo tanto, dentro de su estructura simbólica, este deseo de integridad.

${ }^{3}$ J. M. Oviedo (2010).

${ }_{5}^{4}$ A. W. Phillips (1962), p. 123.

${ }^{5}$ J. Lacan (1978), pp. 261-262.

${ }_{7}^{6}$ A. W. Phillips (1962), p. 142.

${ }^{7}$ La fundamental dualidad inherente al sistema poético velardeano apoya, como justamente ha sido reconocido por mucha crítica, en la sustancial oposición dicotómica entre espiritualidad cristiana y fisicidad profana. A este propósito véanse, entre otros, A. W. Phillips (1962) y A. García Morales (2010). A este asunto está totalmente dedicado el trabajo de E. R. Huchim (2011).

${ }^{8}$ Siempre en el marco de la antes mencionada dicotomía entre religioso y profano, Martha L. Canfield afirma a este propósito: "la meta no alcanzada es siempre una Citeres, pero legitimada en el cuadro de las instituciones cristianas. La meta no alcanzada es el matrimonio" (1981, p. 9). 
En López Velarde como en Petrarca asistimos, aunque con modulaciones diferentes, a este mismo proceso que se acaba de describir' ${ }^{9}$ una conciencia que, escribiendo, se escribe a sí misma en la oscilación del deseo, siguiendo el ritmo secreto y la sintaxis discontinua del erotismo. Resulta entonces una misma tendencia que es un análogo impulso generativo de los textos: esa que encuentra en el sentimiento amoroso el medio privilegiado para que se realice la transferencia en materia verbal, dentro del discurso poético, del yo escribiente, en un constante proceso de proyección del sujeto en la materialidad lingüística.

El amor se configura entonces, no como capítulo biográfico en las vidas de los poetas, sino como transfiguración de un itinerario de autorreflexión: es el medio más adecuado para representar simbólicamente el conflicto que atormenta al sujeto, proporcionando, al mismo tiempo que plantea ese estado de contradicción, el camino para su definitiva resolución. Una lírica amorosa que se define "non più come spazio della rappresentazione rituale dei rapporti interpersonali, ma come spazio dell'io e della soggettività" ${ }^{\prime 10}$. El amor, en su recreación literaria, se convierte en método de indagación íntima del sujeto que, escribiéndose, lo escribe: es instrumento de búsqueda identitaria.

Toda poesía amorosa se centra en la figura de la dama, del otro distinto de sí o, recuperando a Lacan, de lo que al yo le falta para lograr unidad, identidad. La dama es simbólicamente el manque, la encarnación del deseo. Fuensanta, figura alrededor de la cual se desarrolla toda la lírica de Ramón López Velarde, y más aún cuando su ausencia resuena en las páginas de Zozobra, puede ser ubicada en el marco de una larga tradición de figuras poéticas femeninas, cuyo origen común es el arquetipo de Laura. Según Canfield, para lo que atañe a la figura de Fuensanta, "hay sin duda un modelo petrarquesco, más presente en López Velarde que en cualquiera de los poetas de su generación [...]" ". El sujeto lírico velardeano, siguiendo el ritmo de sus contradicciones -que son íntimas oscilaciones-, construye a Fuensanta como entidad divina y abstracta, ya desde composiciones muy tempranas hasta la declaración más explícita de "Canonización", poema incluido en La sangre devota: la amada pierde cualquier connotación humana y se convierte plenamente en criatura espiritual.

Sin embargo, la función desempeñada por Fuensanta a lo largo de la lírica velardeana no se corresponde del todo con la de Laura en el Canzoniere de Petrarca: de hecho, esta última podría ser considerada como un símbolo integral único y polisémico- cuya ambigüedad, tal cual emerge de las páginas del Canzoniere, refleja fielmente la oscilación del sujeto: Laura es alternativamente la mujer ángel cuyo amor permitiría la salvación y el artífice que induce al "giovanil

\footnotetext{
${ }^{9}$ El primero en leer desde esta perspectiva el Canzoniere de Petrarca ha sido S. Agosti (1993).

${ }^{10}$ M. Santagata (1999), p. 8.

${ }^{11}$ M. Canfield (1981), p. 34.
} 
errore" (soneto 1) ${ }^{12}$, en el doble sentido de desviarse y vagar. Fuensanta, al contrario, no constituyendo el único personaje femenino en los versos del poeta mexicano, corresponde exclusivamente a un antes y un después de unidad y pacificación: es el objeto inalcanzable del deseo ${ }^{13}$. Es lo que el yo querría ser, lo que posiblemente ya ha sido, lo que anhela volver a ser. La proliferación simbólica -la presencia de numerosos y diferentes personajes femeninos- atribuye a más que a una mujer el papel de representación de las tensiones opuestas pero simultáneas del sujeto; esto permite entonces configurar unívocamente a Fuensanta, cosa imposible en el caso petrarquesco de Laura.

La divinización de la dama lleva entonces a una descarnalización de la misma y, si se lee esto en su acepción lingüística, a un vaciamiento de su materia verbal. Este mecanismo de abstracción del significante priva a este último de su normal función referencial, convirtiéndolo en un signo más de aquel código que Gianfranco Contini definiera como hecho de "paroles pratiquement vides, donc toutes prêtes à se remplir d'allusions sémantiques" ${ }^{14}$; lengua que, ya incapaz de representar la realidad, es el medio del cual el sujeto hablante se sirve para la proyección textual de sí mismo. La divinización de la figura de la dama $-\mathrm{y}$, por ende, los procesos de abstracción y de vaciamiento- exige, en el marco de una gramática poética ya establecida, fases muy precisas de realización. Siguiendo una línea ya inaugurada por Petrarca, el escritor mexicano necesita, en primera instancia, construir artificiosamente un mundo donde las características de sacralidad de la dama puedan desarrollarse en coherencia simbólica con el resto de los elementos.

\section{Construcción del paisaje}

En un discurso solipsista y regulado por los ritmos del erotismo -con sus oscilaciones y contradicciones-, magistralmente sintetizado en la imagen velardeana del péndulo ${ }^{15}$, es obvio que la configuración poética del paisaje -entendiendo con esto cualquier tipología de ambientación y también de elementos que contribuyen a una colocación ambiental de lo que el texto evoca- resulta irremediablemente regulada por el mismo principio. Por un lado, el escenario, constituyendo parte activa de aquel proceso de significación que prevé el espacio del texto como el lugar donde el sujeto se construye y estructura, deberá constituir

\footnotetext{
${ }^{12}$ Todas las citas del Canzoniere de Petrarca se refieren a la edición crítica de M. Santagata (2004).

${ }^{13}$ Sobre la figura de Fuensanta y su rol en la poesía velardeana véase el interesante ensayo de A. W. Phillips “Otra vez Fuensanta: despedida y reencuentro” (1988, pp. 31-49).

${ }^{14}$ G. Contini (1970), p. 193.

${ }^{15}$ Ejemplar, en este caso, es el poema "Nuestras vidas son péndulos", incluido en La Sangre Devota.
} 
un significante más de un significado único: el yo y su íntima naturaleza ${ }^{16}$; por otro lado, y en consecuencia de este último aspecto, deberá declinarse siguiendo un esquema sustancialmente binario y opositivo, tal cual se estructura el erotismo, movimiento oscilatorio y, por su naturaleza, contradictorio, ambivalente ${ }^{17}$. Además, su relación semántica con la figura de la dama deberá ser la de la correspondencia y de la intercambiabilidad de atributos, siempre en consecuencia de la sustancial equivalencia por la cual cada elemento textual resulta concretización lingüística del sujeto que lo crea.

En la poesía de Ramón López Velarde hay un claro recorrido de definición simbólica de la amada, Fuensanta, que, desde una primera fase de descarnalización del espacio que la rodea, llega hasta la santificación de su figura. Ya los poemas escritos en el lapso de tiempo que va de 1905 a 1912, recogidos póstumamente bajo el título de Primeras poesías, aunque no puedan ser considerados expresiones maduras de la poética velardeana, proporcionan pruebas tangibles de las etapas de construcción mítica de la figura de Fuensanta. Un poema en particular, "En tu casa desierta", resulta interesante para investigar cómo van definiéndose los espacios relacionados con la dama en la lírica del mexicano.

El alma llena de recogimiento, mudos los labios, me detengo en cada lugar de tu mansión, ensimismada cual si la fatigase un pensamiento.

El naranjo medita. En el momento en que estoy en tu alcoba, la almohada me dice que en la noche prolongada tu rostro tibio la dará contento.

\footnotetext{
${ }^{16}$ A esto debe ser reconducida la constante tendencia del sujeto lírico velardeano, ya enfatizada por Phillips, a "identificarse espiritualmente con fenómenos exteriores de la realidad [...], con un objeto fuera de sí mismo, para expresar inesperadas dimensiones en el autoanálisis de su ser contradictorio" (A. W. Phillips, 1962, p. 129). Sin embargo, Phillips parece contradecirse al plantear, algunas páginas después, una subdivisión de la poesía velardeana en dos vertientes distintas, una subjetiva y otra objetiva. En esta última cabrían todos esos poemas que tienen como tema central la provincia y como finalidad la voluntad del sujeto "para intentar captar la médula de su circunstancia mexicana" (p. 182). En nuestra opinión el paisaje siempre es funcional, en la poesía velardeana, a una objetivación del sujeto poético mismo y de su contradictoria interioridad, de acuerdo con la primera afirmación de Phillips.

${ }^{17} \mathrm{La}$ recurrencia de imágenes relacionadas con los campos semánticos de la oscilación y la suspensión es elemento revelador de la configuración erótica del texto poético. Sobre este asunto véase el interesante trabajo de A. W. Phillips (1998).
} 
Honda es la paz... Pero la angustia crece al mirar que no vuelves. Hace ruido el viento entre las hojas, y parece

que en el patio se quejan los difuntos...

¡Es el naranjo, que al temer tu olvido me está invitando a que lloremos juntos! ${ }^{18}$

El soneto es la evocación del cuarto de la amada. Sin embargo, en estos versos todo es abstracción, el escenario se vuelve proyección simbólica de la interioridad del sujeto y de sus deseos. Los paralelismos entre el yo poético y el ambiente son constantes y rigen todo el poema. A su alma se superpone la atmósfera de la casa, "ensimismada" (v. 3) o sea ya transfigurada en persona, en voz auto-meditativa, de donde el paralelo directo con la voz poética; ambas se pierden en el sueño de la mujer, ambas anhelan su presencia. El naranjo, elemento central de la escena, dado su directo paralelismo con el sujeto (vv. 13-14), pierde su connotación de elemento espacial descriptivo, para convertirse en reflejo de la preocupación de la voz poética sobre la posibilidad de no volver a encontrar a la amada; encuentro que sería comunión, unión de los opuestos y su definitiva pacificación en la integridad del sujeto. En la escena presentada, diciéndolo con un verso de "Promesa", "todas las cosas conversan" (v. 12) ${ }^{19}$. Sin embargo, el murmullo que sube de las palabras escritas del poema es la recreación múltiple de un monólogo, su infinita declinación en materia verbal, que al mismo tiempo lo amplifica y lo dispersa. Es el mismo poeta que medita y se acongoja proyectando su angustia en los objetos que lo rodean y que han estado en contacto con la amada. El diálogo que establece con los elementos ambientales es soliloquio, es auto-interrogación.

El poema es una primera manifestación de la tendencia velardeana hacia la abstracción del paisaje cuando éste se encuentra relacionado con la figura de Fuensanta y en Primeras poesías, como atestigua Martha Canfield, los ejemplos abundan:

En los múltiples poemas a la Amada, el paisaje o desaparece (v. "Huérfano quedará", "Ella", “Alejandrinos eclesiásticos", "Tema II”, “Tu voz profética") o se trata simplemente de un lago que simboliza el inconsciente - o, en términos velardeanos, el alma - o bien se trata de alusiones muy generales y - se diría despersonalizadas a flores, pájaros y aun casas, fuentes o balcones que adquieren inmediatamente un valor simbólico ${ }^{20}$.

\footnotetext{
${ }^{18}$ R. López Velarde (1998), p. 40.

${ }^{19}$ R. López Velarde (1998), p. 11.

${ }^{20}$ M. L. Canfield (1981), p. 28.
} 
Otro texto, "Viaje al terruño", permite profundizar la relación que se establece entre el paisaje y la amada para sacar algunas conclusiones sobre las modulaciones simbólicas del escenario:
De la noche en el arcano
llega al éxtasis la mente
si beso devotamente
los pétalos de tu mano.
En la blancura del llano
una fantasía rara
las lagunas comparara,
azuladas y tranquilas,
con tus azules pupilas
en la nieve de tu cara ${ }^{21}$.

Estos versos establecen un contacto directo entre el paisaje y la amada. Sus manos, en la iluminación de la metáfora, son pétalos, mientras que las lagunas diseminadas en el llano, a través de un elaborado juego comparativo a cuatro términos, evocan directamente el rostro de la mujer. La provincia mexicana, referente originario ya dejado atrás por el mismo significante que lo designaba, adquiere ahora un aspecto inmaterial. El proceso de ver $\operatorname{como}^{22}$ por el cual el escenario solo tiene la función de evocar a la amada identificándose con ella, vacía de cualquier otra referencialidad los elementos implicados. La distancia del objeto deseado comporta la proyección de algunas partes de ello (mano, pupilas, cara) en objetos materiales cuya única función es la del fetiche.

Es necesario ahora evocar una de las canciones más célebres del Canzoniere de Petrarca, "Chiare fresche e dolci acque" (canción 126) que, análogamente a "En tu casa desierta", se estructura como un diálogo entre el sujeto y el escenario. Como se ha mencionado antes, la construcción de un ambiente inmaterial es necesaria para la canonización de la mujer. El paisaje es directamente contiguo a la imagen de la amada y, además, es ocasión para una continua transmigración de elementos de una al otro y viceversa. Desde el empleo de recursos tradicionales en la descripción de la mujer en su estrecha relación con la naturaleza, se pasa, en un salto perceptivo y lingüístico fundamental, a la sustitución afectiva, a la igualación de los elementos.

Ya desde el inicio de la composición se establece una neta contigüidad entre la figura de la amada y la naturaleza: la presencia de Laura surge del agua y de la hierba, la intercambiabilidad entre su esencia y la de los elementos del escenario es espontánea. Sin embargo, en los versos que cierran la canción, el espacio se transfigura en una dimensión totalmente diferente. A la realidad de las riberas del

\footnotetext{
${ }^{21}$ R. López Velarde (1998), p. 60 (vv. 31-40).

${ }^{22}$ Me refiero a este concepto tal como aparece en P. Ricoeur (2010), p. 280.
} 
Sorga, en Valchiusa, que todavía caracterizaba, en cierta medida miméticamente, la primera parte, se contrapone una dimensión imaginaria e irreal cuya esencia es exclusivamente espiritual y que borra por completo la percepción realista del ambiente. Laura se vuelve definitivamente espíritu divino ("Costei per fermo nacque in paradiso", v. 56) y Valchiusa adquiere las formas idealizadas del paraíso ("Qui come venn'io, o quando?; / credendo d'esser in ciel, non là dov'era", vv. 63-64).

Hemos visto cómo la idealización del paisaje responde a la necesidad de descarnalización de la mujer amada. En efecto, el ser cuyo rostro el artista quiere pintar como perfecto e independiente del tiempo y del espacio -en cuanto imagen de un estado no conflictivo de sí mismo- deberá necesariamente moverse en una dimensión cuyas coordenadas sensibles hayan sido borradas por completo. El mundo de este ser deberá entonces compartir con él una misma esencia: sus manifestaciones particulares deberán ser puestas con él en constante contacto osmótico. "Valchiusa è stata sacralizzata dal contatto con la donna" 23 y lo mismo puede decirse de la provincia velardeana en su relación con Fuensanta: "Fuensanta y la provincia forman un mundo mítico, perdido, pero también esperado, siempre anterior o futuro, nunca presente" 24 .

Rivas Sáinz encuentra en el procedimiento metafórico de la "metamorfosis o transformación" ${ }^{25}$ uno de los recursos estilísticos privilegiados por López Velarde. A este procedimiento figurativo pertenece esa tendencia por la cual es posible obtener una completa identificación de una realidad concreta -ya transfigurada, vaciada- con la figura de la amada. Otro elemento ambiental puede ayudar a comprender este fenómeno: las flores. Siguiendo un esquema propio de toda poesía amorosa, a partir de los provenzales hasta llegar a la reelaboración petrarquista, la figura de Fuensanta está constantemente rodeada de flores. Éstas, sin embargo, más que elemento paisajístico concreto, confunden su esencia con la de la amada misma: son simulacros fragmentados de su presencia en el lugar de su ausencia.

En la poesía de López Velarde es fácil notar el paso gradual desde una simple comparación de elementos, útil para una constante adjetivación de la figura de Fuensanta, a la identificación del sustantivo con el calificativo: de la comparación a la metáfora. En el poema "Elogio a Fuensanta" el cuerpo de la dama, ya al final del proceso descrito, es un nardo (v. 22) ${ }^{26}$ y en "Ser una casta pequeñez" su pecho es un "naranjo en flor" (v. 13) ${ }^{27}$. Lo mismo pasa en relación con el sentimiento amoroso, en su configuración positiva, del cual Fuensanta es el simulacro. Dice el poeta en "Tu voz profética" con una metáfora de gran complejidad, desarrollada en varios

\footnotetext{
${ }^{23}$ M. Santagata (1992), p. 176.

${ }^{24}$ A. García Morales (2010).

${ }^{25}$ A. Rivas Sáinz (1998), p. 478.

${ }^{26}$ R. López Velarde (1998), p. 23.

${ }^{27}$ R. López Velarde (1998), p. 58.
} 
niveles: "y nuestro dulce noviazgo / será, Fuensanta, una flor / con un pétalo de enigma / y otro pétalo de amor" (vv. 46-49) 28.

Se ha dicho precedentemente que el paisaje, como cualquier otro elemento semántico de una lírica amorosa así estructurada, resultará organizado según esquemas de oposiciones binarias. Al ser la psicología fragmentada del yo poético el único referente del discurso, el ambiente deberá declinarse de manera diferente y hasta contradictoria, confirmando un sustancial bipolarismo isotópico del texto. Así, en Petrarca asistimos a la alternancia, a lo largo del Canzoniere, entre el escenario irreal e idealizado de un ambiente de origen biográfico, Valchiusa, sacralizado por el contacto con la mujer amada; y una geografía que, representada por la ciudad de Aviñón, al contrario, resulta impregnada de historicidad, es decir sometida al paso del tiempo, a la muerte, a la frustración de cualquier esperanza de unidad y de salvación.

Un esquema análogo en la organización de las ambientaciones puede reconocerse también en la poesía velardeana, aunque el discurso, en la modernidad novecentista, resulte problematizado con respecto a la lección tradicional primaria. A la provincia de Fuensanta que, como se ha visto, nada tiene de realista, constituyéndose ya como pura y vacía materia verbal, se oponen no uno sino, al menos, dos escenarios distintos. Por un lado tenemos, de acuerdo con la tradicional oposición resumible en la fórmula del menosprecio de corte y alabanza de aldea ${ }^{29}$, la ciudad, elemento geográfico que encarna en sí la morbosidad y la perdición de un eros terrible y destructor. Al lado de la faz oscura de la Laura petrarquesca, tentación que desvía del amor salvífico y divino, encontramos los amoríos

\footnotetext{
${ }^{28}$ R. López Velarde (1998), p. 43.

${ }^{29}$ Canfield establece una genealogía para este elemento particular de la poesía de López Velarde: "El 'elogio de la provincia y el desprecio de la ciudad', variante moderna del clásico 'menosprecio de corte y alabanza de aldea', ha llegado a López Velarde probablemente a través de la mediación de Andrés Bello, que un siglo antes que él pregonaba ya las virtudes del campo y del amor agreste y prevenía contra los falaces placeres de las ciudades y sus funestas tentaciones" (1981, p. 12). Aquí Canfield se refiere esencialmente a la Silva a la agricultura de la zona tórrida de Bello de 1826, donde se lee: “¡Oh jóvenes naciones, que ceñida / alzáis sobre el atónito Occidente / de tempranos laureles la cabeza! / Honrad al campo, honrad la simple vida / del labrador y su frugal llaneza. / Así tendrán en vos perpetuamente / la libertad morada, / y freno la ambición, y la ley templo" (vv. 351-358). Es interesante notar que Bello fue atento lector de Petrarca y que tradujo, aunque parcialmente, solo los primeros once versos, la famosísima canción civil “All'Italia". También Petrarca, en este poema, exalta la patria valiéndose de sus elementos naturales, oponiéndolos a los intereses del poder de las ciudades, en constante lucha entre sí. La oposición ciudad/provincia en Petrarca es de segura raíz bíblica, inspirándose el poeta a la concepción de la ciudad como Babilonia. Para este concepto, que aparece a menudo en las páginas del Canzoniere, véanse, en particular, los sonetos 114, 137, 138, 139.
} 
-múltiples y por eso peligrosos, no estables- que el yo lírico velardeano tiene en la metrópoli.

Sin embargo, López Velarde problematiza el asunto: en la estricta dicotomía a la cual se acaba de hacer referencia - provincia y ciudad, pureza y perdición- se inserta una ambientación intermedia que podría definirse como "contaminada": no es esta la provincia de Fuensanta sino la de la multitud de provincianas que animan páginas intensísimas de la poesía velardeana. Lejos de configurarse esta última como paisaje irreal e idealizado, resulta, al contrario, el lugar de una versificación prosaica e irónica, contaminada en profundidad por la historia que, como vimos, no es otra cosa sino la muerte misma. Si hay una relación entre esta provincia y el ambiente donde se mueve Fuensanta es la de la degradación de este último. La inaccesibilidad del objeto deseado lleva al sujeto a multiplicarlo, disgregándolo en una multitud de otras figuras femeninas. Proceso de degradación que, por un lado, permite una mayor cercanía de lo lejano, una mayor accesibilidad de lo que antes resultaba inaccesible pero que, al mismo tiempo, impide la realización de una definitiva comunión de los términos de la relación dialéctica y, con eso, la unidad identitaria del sujeto. La provincia resultará entonces afectada por la tragedia de la vida cotidiana, la ciudad no será ahora dimensión a esta extraña sino que se establecerá un continuo intercambio de efluvios negativos entre las dos, como en los poemas "A las jerezanas mártires" y "Las desterradas", ambos incluidos en Zozobra. La perfección de la construcción estética del mito de la provincia, sede paradisíaca en cuyo centro reside la mujer amada, va perdiendo su benéfica seguridad al paso que la voz poética se va dando cuenta de la falacia de su artificio.

\section{Conclusiones}

El amor es un tema que proporciona una estructura: o más bien, el erotismo es capaz de reflejar estructuralmente cierta tipología del estado psicológico. Su fuerza literaria, ya entendida por Petrarca, es su aptitud para constituirse como un esquema isotópico fundamental del discurso poético. Con esto debe entenderse la capacidad estructurante del tema erótico-amoroso como tendencia organizativa según esquemas correlativos de oposición binaria: organización ya reconocida como huella moderna fundamental de la lección primaria del Canzoniere ${ }^{30}$. Como se ha señalado, también el paisaje y, en general, todos los elementos ambientales de este tipo de poesía, corresponden a la misma estructuración binaria y opositiva, aunque el discurso poético moderno haga más complejo el esquema de relaciones. El paisaje entonces es de por sí el texto, escritura que refleja en su organización la arquitectura del sujeto que la escribe.

\footnotetext{
${ }^{30}$ Para la cuestión de la correlación como estrategia textual petrarquista véase el interesante ensayo de D. Alonso (1950).
} 
Centrándose en particular en cierto tipo de ambientación idealizada y abstracta, y poniendo esta última en relación dialéctica con los demás escenarios poéticos de López Velarde, se ha intentado bosquejar una primera serie de correspondencias entre la poesía del mexicano y la arquetípica lección lírica del Canzoniere petrarquesco, proponiendo cómo ciertas similitudes de argumento resulten determinadas por la necesidad de estructurar el discurso poético según un principio análogo. Sin lugar a dudas, las relaciones, más que simples coincidencias, revelan una supervivencia de las coordenadas fundamentales y más profundas de la poética petrarquesca, "secondo un percorso genealogico sotterraneo ma effettivo, in alcune delle esperienze di prima grandeza" - baste pensar en la ya reconocida filiación petrarquista de escritores como Góngora, Mallarmé y Leopardi - "che inaugurano [...] la modernità letteraria" 31 .

\section{Obras citadas}

Agosti, Stefano: Gli occhi e le chiome: per una lettura psicoanalitica del Canzoniere di Petrarca, Milano, Feltrinelli, 1993.

Agosti, Stefano: "Petrarca e la modernità letteraria", en Forme del testo. Linguistica, semiologia, psicoanalisi, Milano, Istituto Editoriale Universitario Cisalpino, 2004, pp. 15-45.

AlONSO, Dámaso: Un aspecto del petrarquismo. La correlación poética, Madrid, Instituto Italiano de Cultura, 1950.

CANFIELD, Martha Luana: La provincia inmutable. Estudios sobre la poesía de Ramón López Velarde, Firenze, D’Anna, 1981.

CONTINI, Gianfranco: "Préhistoire de l'aura de Pétrarque", en Varianti e altra linguistica, Torino, Einaudi, 1970, pp. 193-199.

GARCía MORALES, Alfonso: "Deseo y represión, mujer y necrofilía en Ramón López Velarde", en Carmen de Mora y Alfonso García Morales (eds.), Escribir el cuerpo. 19 asedios desde la literatura hispanoamericana, Sevilla, Universidad de Sevilla, 2003, pp. 111-133. Edición digitalizada consultada: Alicante, Biblioteca Virtual Miguel de Cervantes, 2010.

HUCHIM, Eduardo R.: "López Velarde: la profana religiosidad", Revista de la Universidad de México, 88 (2011), pp. 39-43.

LACAN, Jaques: Le séminaire, Livre II, Le moi dans la théorie de Freud et dans la technique de la psychanalyse, Paris, Edition du Seuil, 1978.

LÓPEZ VelaRde, Ramón: Obra poética, edición crítica de José Luis Martínez, Madrid, Colección Archivos, 1998.

${ }^{31}$ S. Agosti (2004), p. 15. 
Oviedo, José Miguel: "López Velarde o el desasosiego", Hispanic Poetry Review, vol. 1, n. 1 (1999), pp. 46-55. Edición digitalizada consultada: Alicante, Biblioteca Virtual Miguel de Cervantes, 2010.

PAZ, Octavio: "El camino de la pasión", en Cuadrivio, México, Editorial Joaquín Mortiz, 1969.

Petrarca, Francesco: Canzoniere, edición de Marco Santagata, Milano, Mondadori, 2004.

PHILLIPS, Allen W.: Ramón López Velarde, el poeta y el prosista, México, Instituto Nacional de Bellas Artes, Departamento de Literatura, 1962.

PhILliPS, Allen W.: Retorno a Ramón López Velarde, México, Instituto Nacional de Bellas Artes, Gobierno del Estado de Zacatecas, Universidad Autónoma de Zacatecas, 1988.

PHILliPS, Allen W.: "Tres procedimientos imaginativos", en LÓPEZ VelaRdE, Ramón (1998), pp. 554-573.

RICOUER, Paul: La metafora viva. Dalla retorica alla poetica: per un linguaggio di rivelazione, Milano, Jaca Books, 2010.

SANTAGATA, Marco: I frammenti dell'anima. Storia e racconto nel Canzoniere di Petrarca, Bologna, Il Mulino, 1992.

SAntagatA, Marco: Amate e amanti. Figure della lirica amorosa fra Dante e Petrarca, Bologna, Il Mulino, 1999.

RIVAS SÁINZ, Arturo: "Sistema arterial del vocabulario", en LÓPEZ Velarde, Ramón (1998), pp. 477-482. 